\title{
Observations on a new disinfectant
}

\author{
A. M. GORDON \\ From the Department of Laboratory Medicine, Belvidere Hospital, Glasgow
}

SYNOPSIS A disinfectant formula (Resiguard) containing picloxydine digluconate, benzalkoniumchloride, and a detergent was examined for antibacterial activity.

Studies in vitro with simulated organic contamination were followed by realistic in-use testso응 employing items of anaesthetic and urological equipment heavily infected with Pseudomonas aeruginos $a$ and contaminated with blood. These showed that a dilution of $1 / 80$ was reliably bacteri $-N_{A}^{N}$ cidal to this resistant organism.

It is concluded that Resiguard is a valuable disinfectant which may reliably be employed in the cleaning and disinfection of items of delicate, non-autoclavable, hospital equipment.

Hospital-acquired infections present a continuing challenge to clinical and laboratory personnel. There is evidence that the patterns of such infections have been undergoing important changes within recent years, infections by the Gram-negative organisms having become more frequent (Finland, Jones, and Barnes, 1959; William, Williams, and Hyams, 1960; Barber, 1961; Selwyn, MacCabe, and Gould, 1964; Williams, Blowers, Garrod, and Shooter, 1966). This is especially relevant to Pseudomonas aeruginosa, a notoriously 'opportunistic' pathogen for debilitated patients in hospital, which possesses a high intrinsic resistance to many currently available antibiotics, and to the majority of traditional hospital disinfectants. Furthermore, recent developments in medical technology have been associated with the introduction of highly intricate equipment many components of which, being non-autoclavable, must be cleaned and disinfected by chemical methods.

Despite the magnitude of these problems, it is apparent that chemical disinfection is a somewhat neglected subject. Previous authoritative reports (Public Health Laboratory Service Committee, 1965; Kelsey and Maurer, 1967) on the testing, evaluation, and use of disinfectants have emphasised that in most hospitals, a wide variety of formulations has been used in a largely empirical, and often quite unrealistic manner, and the need for a rational disinfectant policy using a limited number of reliable multipurpose agents has been stressed. A possible candidate for this role is a new disinfectant formula, Resiguard ${ }^{1}$, comprising three Received for publication 23 October 1968.

${ }^{1}$ Nicholas Laboratories Ltd. active principles. These are picloxydine digluconate, $a \vec{c}$ broad-spectrum antibacterial compound possessingo a biguanide structure: octylphenoxy-polyethoxy-: ethanol, a nonionic detergent: and the quaternaryo ammonium compound, benzalkonium chloride.

\section{METHODS}

INVESTIGATIONS IN VITRO In view of previous reports 3 (Lowbury, 1951; Burdon and Whitby, 1967; Brit. med.Э $J ., 1967)$ that bacteria, especially pseudomonas, mayọ proliferate in solutions of some disinfectants, preliminary experiments in vitro were undertaken to establish whethero resistant Gram-negative bacilli would survive and multiply in dilutions of Resiguard stored over prolonged periods. The organisms chosen were Pseudomonaso aeruginosa NCTC 6749 and Klebsiella aerogenes NCTC 8172 , and the method employed was similar to that of Burdon and Whitby (1967).

Duplicate doubling dilutions of a stock concentrate of the disinfectant were made, in $10 \mathrm{ml}$ aliquots, with distilled water in laboratory glassware, and these were 0 inoculated with a straight wire from single colonies of the two strains grown overnight on nutrient agar at $37^{\circ} \mathbf{C}$. Dilutions ranging from $1 / 10$ to $1 / 2,560$ were tested. At intervals of 48 hours, $0.2 \mathrm{ml}$ amounts of each disinfectanto dilution were subcultured to $5 \mathrm{ml}$ nutrient broths and on nutrient agar plates, the recovery media being incubated at $37^{\circ} \mathrm{C}$ for 72 hours. Subcultivations were performed fores? a period of four weeks.

A series of bactericidal tests in tubes was conducted, $\frac{T}{\vec{P}}$ employing Resiguard at dilutions of $1 / 80(1.25 \%), 1 / 160$ 呅 $(0.625 \%)$, and $1 / 320(0.3 \%)$ against Staphylococcus aureus NCTC 4163, Escherichia coli NCTC 9002, and Pseudomonas aeruginosa NCTC 6749. Dilutions of dis-O infectant were made in nutrient broth and in $20 \%$ serum broth, and the test organisms were grown in nutriento 
broth at $37^{\circ} \mathrm{C}$ for 18 hours; $0.5 \mathrm{ml}$ of broth culture was added to $4.5 \mathrm{ml}$ of the disinfectant dilutions at room temperature. At intervals of $2,4,6,8,10$, and 15 minutes, 3 standard loopfuls of fluid were transferred to nutrient agar plates and 1 loopful to $5 \mathrm{ml}$ of nutrient broth. Lubrol W ( $5 \%$ ), a known inactivator of quaternary ammonium compounds (British Standards Institution, 1960; Rubbo and Gardner, 1965), was incorporated in the recovery broth and nutrient agar plates as a neutralizer of possibly bacteriostatic quantities of disinfectant. The plates and broths were incubated at $37^{\circ} \mathrm{C}$ for 24 hours, after which all apparently sterile broths were subcultured to nutrient agar, and incubation continued for a further 24 hours. The presence or absence of bacterial growth after exposure to dilutions of Resiguard for increasing periods of time was recorded.

A further assessment in vitro of the disinfectant was undertaken using the stringent use-dilution capacity test of Kelsey, Beeby, and Whitehouse (1965) and employing Pseudomonas aeruginosa NCTC 6749 as the test organism. The latter was grown overnight at $37^{\circ} \mathrm{C}$ in $20 \mathrm{ml}$ amounts of Oxoid no. 2 nutrient broth, and was used unaltered in the definitive test of the disinfectant in the absence of organic contamination. A yeast suspension, simulating organic spoilage, was made as for the Chick Martin test, to contain $5 \%$ dry weight yeast at $p \mathrm{H} \mathrm{7.0.} \mathrm{A} \mathrm{yeast}$ suspension of Pseudomonas aeruginosa was also prepared by centrifugation of a nutrient broth culture, and resuspension of the sediment in $20 \mathrm{ml}$ of the yeast preparation. Dilutions of Resiguard were made in sterile distilled water. In the actual test, $12 \mathrm{ml}$ of disinfectant was placed in a sterile bottle and at 10-minute intervals $2 \mathrm{ml}$ of the test organism suspension was added. Eight minutes after each addition, the mixture was subcultured with a 50-dropper pipette, 5 drops being placed on a nutrient agar plate (containing $5 \%$ Lubrol W) and 1 drop being added to each of two volumes of $20 \mathrm{ml}$ nutrient broth. The test was allowed to continue until six additions of the test organism had been made. The plates and broths were incubated at $37^{\circ} \mathrm{C}$ for 48 hours, after which the results were recorded. A use-dilution of the disinfectant was judged to have passed the test and to be satisfactory if three or more additions of organisms could be made before recovering a positive culture.

'IN-USE' INVESTIGATIONS A number of 'in-use' tests were conducted using items of equipment likely to be subjected to gross protein contamination from exudates, blood, etc, and thus presenting particular disinfection difficulties. The items chosen were corrugated anaesthetic rubber tubing, an endotracheal tube, and a cystoscope. Resiguard was tested at dilutions of $1 / 80$ and $1 / 160$ in $20 \%$ serum, and a clinical isolate of Pseudomonas aeruginosa was employed to contaminate the equipment. The corrugated anaesthetic tubing was cut into cylinders of approximately 2 inches, and each was contaminated by total immersion in an overnight $10 \%$ blood-broth culture of the Pseudomonas strain. Sections of contaminated tubing were withdrawn, allowed to dry on a sterile surface and after taking pre-disinfection swabs from their lumina, separate cylinders were immersed in individual beakers of Resiguard at the chosen in-use dilutions. At intervals of $2,5,10,20$, and 30 minutes, a section of tubing was removed, rinsed in sterile saline, and swabs were taken from the inner lumen.

The endotracheal tube and the cystoscope were heavily contaminated by total immersion in basins of bloodbroth containing the Pseudomonas aeruginosa culture. Preliminary swabs were taken from the lumina of these articles, after which the equipment was immersed in disinfectant. At intervals of 2, 5, 10, 15, 20, and 30 minutes they were removed, rinsed with sterile saline, and their lumina swabbed. All swabs were inoculated into nutrient broth, and after overnight incubation at $37^{\circ} \mathrm{C}$, subcultures were made to cetrimide agar plates, which were incubated for a further 24 hours.

\section{RESULTS}

SURVIVAL OF GRAM-NEGATIVE ORGANISMS IN STORED RESIGUARD DILUTIONS No pseumodomas or klebsiellae were recovered from any of the dilutions of disinfectant, even after storage of the solutions for up to four weeks at room temperature.

BACTERICIDAL TUBE DILUTION TESTS IN VITRO Table I shows the minimum contact time required for a $100 \%$ kill of the chosen test organisms, using Resiguard at the three test dilutions. The highest resistance to the disinfectant in vitro was exhibited by the Pseudomonas aeruginosa strain, which survived for more than 15 minutes when exposed to the disinfectant at a dilution of $1 / 320$ in $20 \%$ serum,

TABLE I

BACTERICIDAL ACTIVITY OF RESIGUARD IN VITRO

Time (min) Required for a 100\% Kill at Stated Dilutions

\begin{tabular}{|c|c|c|c|c|c|}
\hline \multicolumn{2}{|l|}{$1 / 80$} & \multicolumn{2}{|l|}{$1 / 160$} & \multicolumn{2}{|l|}{$1 / 320$} \\
\hline No Serum & $+20 \%$ Serum & No Serum & $+20 \%$ Serum & No Serum & $+20 \%$ Serum \\
\hline$<2$ & $<2$ & $<2$ & $<2$ & $<2$ & $<2$ \\
\hline$<2$ & $<2$ & $<2$ & $<4$ & $<4$ & $<6$ \\
\hline$<2$ & $<2$ & $<4$ & $<8$ & $<6$ & $<15$ \\
\hline
\end{tabular}


TABLE II

USE-DILUTION CAPACITY TEST OF RESIGUARD

Dilution Medium Addition Number

\begin{tabular}{llllllll} 
& & & & & & Result \\
\cline { 3 - 7 } & Broth & - & - & - & - & - & -
\end{tabular}

$1 / 80$

$1 / 60$

+ Yeast $\left\{\begin{array}{l}\text { Broth } \\ \text { Agar }\end{array}\right.$
- Yeast $\left\{\begin{array}{l}\text { Broth } \\ \text { Agar }\end{array}\right.$

$$
\begin{aligned}
& \text { + Yeast }\left\{\begin{array}{l}
\text { Broth } \\
\text { Agar }
\end{array}\right. \\
& 1 / 320 \quad-\text { Yeast }\left\{\begin{array}{l}
\text { Broth } \\
\text { Agar }
\end{array}\right.
\end{aligned}
$$

$$
+ \text { Yeast }\left\{\begin{array}{l}
\text { Broth } \\
\text { Agar }
\end{array}\right.
$$

Test organism : Pseudomonas aeruginosa, NCTC 6749.

c : indicates number of bacterial colonies.

CO : " confluent bacterial growth.

TABLE III

DISINFECTION OF PSEUDOMONAS-CONTAMINATED EQUIPMENT BY RESIGUARD

Dilution

\begin{tabular}{|c|c|c|c|c|c|c|c|}
\hline & & 2 & 5 & 10 & 15 & 20 & 30 \\
\hline $1 / 80$ & $\begin{array}{l}\text { Endotracheal tube } \\
\text { Corrugated tubing } \\
\text { Cystoscope }\end{array}$ & $\begin{array}{l}+ \\
+ \\
+\end{array}$ & $\frac{+}{+}$ & $\frac{-}{+}$ & 三 & $\bar{z}$ & $\bar{z}$ \\
\hline $1 / 160$ & $\begin{array}{l}\text { Endotracheal tube } \\
\text { Corrugated tubing } \\
\text { Cystoscope }\end{array}$ & $\begin{array}{l}+ \\
+ \\
+\end{array}$ & $\begin{array}{l}+ \\
+ \\
+\end{array}$ & $\frac{t}{t}$ & $\frac{+}{+}$ & $\bar{t}$ & $\begin{array}{l}\bar{z} \\
\end{array}$ \\
\hline
\end{tabular}
Item

Post-Immersion (minutes)

though a rapid bactericidal effect in vitro was obtained at the $1 / 80$ dilution.

USE-DILUTION CAPACITY TESTS The results of these tests, employing Pseudomonas aeruginosa as the test organism, are summarized in Table II. Resiguard passed this test at a $1 / 80$ dilution, but narrowly failed at $1 / 160$ in the presence of protein spoilage: the $1 / 320$ dilution was not satisfactory even in the absence of protein contamination.

IN-USE TESTS Table III shows the results of the in-use tests on the items of medical equipment. All three articles were successfully disinfected by a $1 / 80$ dilution in less than 15 minutes. Pseudomonas aeruginosa could still be recovered from the lumen of the sheath of the cystoscope after 20 minutes' exposure to a $1 / 160$ dilution of Resiguard, although $\stackrel{\circ}{\supset}$ disinfection was complete after 30 minutes.

\section{DISCUSSION}

Although it is generally accepted that chemicals aren inferior to physical methods of killing pathogenic N microorganisms, and should be used 'only when physical methods are impossible or impracticable (Public Health Laboratory Service Committee, 1965), it is probable that chemical disinfection willo always play an important contributory role in reducing hospital crossinfection problems. Many excellent disinfectants have appeared within recento years, though none is ideal. The perfect disinfectant should be rapidly lethal to a wide range of Grampositive and Gram-negative bacteria, including Pseudomonas spp., and possess viricidal, fungicidal,, 0 
and sporicidal activity. Protein contamination, such as blood or pus, should not significantly reduce the activity of the disinfectant. The agent should possess efficient cleaning or detergent properties, should not stain or corrode instruments or fabrics, nor cause allergic reactions. A realistic cost must also be borne in mind.

Resiguard is a concentrate incorporating picloxydine (as digluconate), benzalkonium chloride, and a non-ionic detergent. While it is miscible with water and alcohols, it is not compatible with soaps or hypochlorite, but the inclusion of a detergent imparts efficient cleaning and grease-removing properties: the diluted fluid is virtually nonirritant, noncorrosive, and nonstaining. Few studies of this disinfectant have yet been reported. Resiguard, however, has been successfully employed for disinfection in the hospital environment (Couston and Campbell, 1967) and in animal houses (Cooper and Rice, 1967). Recently its use in the disinfection of a mechanical ventilator has been reported (Meadows, Richardson, Fish, and Williams, 1968), while Holman and Pexton (1968) have evaluated the activity of Resiguard in vitro and its efficiency as a means of environmental decontamination. The object of the present investigation was to assess the antibacterial activity of this disinfectant formula. The effect of Resiguard on bacterial spores, fungi, and viruses was not systematically examined, although limited personal experience (Gordon, unpublished results) has confirmed its usefulness as a fungicide under conditions of heavy fungal contamination in a virological laboratory. Significant antifungal activity might be anticipated by virtue of the benzalkonium chloride component (Reddish, 1957), and this quaternary ammonium compound has also been shown to be active against numerous viruses, with the notable exception of poliovirus (Armstrong and Froelich, 1964).

In assessing the merits of any disinfectant one must be conscious of the limitations of some of the traditional tests in vitro, and of the need for stringent realistic tests using highly resistant organisms in the presence of gross organic contamination. To date, no single test is completely satisfactory, although 'use-dilution' tests such as the AOAC use-dilution method of Stuart, Ortenzio, and Friedl (1953), are superior to the 'phenol coefficient' methods originated by Rideal and Walker (1903). Kelsey et al (1965) described the capacity use-dilution test on which the principal in vitro assessment of Resiguard in this investigation, has been based. The results in vitro have confirmed that a use-dilution of $1 / 160$ is reliably bactericidal in 'clean' situations, although where marked organic contamination is known or suspected the disinfectant should be employed at a dilution of $1 / 80$.
Disinfectant solutions themselves are not immune from bacterial contamination (Lowbury, 1951; Anderson and Keynes, 1958; Kelsey and Maurer, 1966; Burdon and Whitby, 1967), and clinical outbreaks of infection, especially of the urinary tract, have been attributed to this cause (Mitchell and Hayward, 1966; Dulake and Kidd, 1966; Moore and Forman, 1966). Burdon and Whitby (1967) have reported the contamination of aqueous solutions of chlorhexidine and of cetrimide-chlorhexidine with species of Pseudomonas, and regular tests for bacterial pollution of pharmaceutical products have been urged, (Brit. med. J., 1967). In laboratory experiments, Burdon and Whitby (1967) showed that the viable count of a Pseudomonas strain increased 100,000 fold during three weeks in $0.05 \%$ chlorhexidine. In the present investigations, however, resistant Pseudomonas and Klebsiella strains did not persist in stock aqueous solutions of Resiguard, even at fairly high dilutions.

The items of anaesthetic and urological equipment chosen for testing were those liable to become heavily contaminated by organic material, thus posing special problems of cleaning and disinfection. In addition, cystoscopes and other endoscopic instruments are delicate items of equipment, since the lens mountings are liable to damage when heated to $100^{\circ} \mathrm{C}$ or higher, so that something less than a full sterilizing heat process may need to be accepted. Pasteurization in water (Francis, 1959) or in steam at subatmospheric pressure (Alder, Brown, and Gillespie, 1966) have been used as well as various methods of chemical disinfection, including alcoholic chlorhexidine (Miller, Gillespie, Linton, Slade, and Mitchell, 1960), and buffered glutaraldehyde (Borick, Dondershine, and Chandler, 1964; Rubbo and Gardner, 1965; O'Brien, Mitchell, Haberman, Rowan, Winford, and Pellet, 1966; Ross, 1966). In the present study, aqueous Resiguard (at 1.25\%) proved effective in eliminating Pseudomonas aeruginosa from a grossly contaminated cystoscope, no organisms being recovered after exposure to the disinfectant for 30 minutes, while immersion of this type of instrument for up to three weeks in Resiguard had no apparent effect on the lens cement and no corrosive action on the metal of the instrument. The performance of alcoholic solutions of Resiguard in endoscope disinfection was not investigated, though this might be expected further to increase the margins of safety. It is considered that Resiguard may find a useful place in the routine or emergency disinfection and storage of non-autoclavable surgical equipment.

Messrs. Nicholas Laboratories kindly supplied generous quantities of Resiguard disinfectant. 


\section{REFERENCES}

Alder, V. G., Brown, A. M., and Gillespie, W. A. (1966). J. clin. Path. 19,83

Anderson, K., and Keynes, R. (1958). Brit. med. J., 2, 274.

Armstrong, J. A., and Froelich, E. J. Appl. Microbiol., 12132 (1964).

Barber, M. (1961). J. clin. Path., 14, 2.

Borick, P. M., Dondershine, F. H.. and Chandler, V. L. (1964). J. Pharm. Sci., 53, 1273.

British Medical Journal (1967), Leading Article, Brit. med. J. 2 , 125.

British Standards Institution (1960). British Standard 3286.

Burdon, D. W., and Whitby, J. L. (1967). Brit. med. J. 2, 153.

Cooper, L. G., and Rice, J. M. (1967). J. Sci. Techol. 13, 58.

Couston, T. A., and Campbell, G. (1967). Med. Offr., 117, (9), 114

Dulake, C., and Kidd, E. (1966). Lancet, 1, 980.

Finland, M., Jones, W. F., Jr., and Barnes, M.W. (1959). J. Amer. med. Ass., 170, 2188.

Francis, A. E. (1959). Proc. roy. Soc. Med., 52, 998.

Holman, R. A., and Pexton, J. M.(1 968). Brit. Hosp. J. Soc. Serv. Rev., 490.

Kelsey, J. C., Beeby, M. M., and Whitehouse, C. W. (1965). Mth. Bull. Minist. Hlth Lab. Serv., 24, 152.

, and Maurer, I. M. (1966). Ibid. 25, 180

- - (1967). Brit. Hosp. J. soc. Serv. Rev., 1744.

Lowbury, E. J. L. (1951). Brit. J. Industr. Med., 8. 22.
Meadows, G. A., Richardson, J. C., Fish, E., and Williams, A. (1968) Brit. J. Anaesth., 40, 71.

Miller, A., Gillespie, W. A., Linton, K. B., Slade, N., and Mitchell므 J. P. (1960). Lancet, 2, 886.

Mitchell, R. G., and Hayward, A. C. (1966). Ibid., 1, 793.

Moore, B., and Forman, A., (1966). Ibid., 2, 929.

O'Brien, H. A., Mitchell, J. D., Jr., Haberman, S., Rowan, D. F Winford, T. E., and Pellet, J. (1966). J. Urol (Baltimore) 95, 429.

Public Health Laboratory Service Committee (1965). Brit. med. J命 $1,408$.

Reddish, G. F., ed. (1957). 'Antiseptics, Disinfectants, fungicides and Chemical and Physical Sterilization', 2nd ed., Lea and Febiger Philadelphia. Kimpton, London.

Rideal, S., and Walker, J. T. A. (1903). J. roy. sanit. Inst., 24, 424 $\overrightarrow{0}$

Ross, P. W. (1966). J. clin. Path., 19, 318. Rubbo, S. D., and Gardner, J. F. (1965). A Review of Sterilization and $\vec{\omega}$
Disinfection. Lloyd-Luke, London.

Selwyn, S., MacCabe, A. F., and Gould, J. C. (1964). Scot, med. J. 9, 409.

Stuart, L. S., Ortenzio, L. F., and Friedl, J. L. (1953). J. Ass. off. agric. Chem. 36, 466

William, R., Williams, E. D., and Hyams, D. E. (1960). Lancet, 1, 376.

Williams, R. E. O., Blowers, R., Garrod, L. P., and Shooter, R. A. (1966). Hospital Infection: Causes and Prevention, 2nd ed.c Lloyd-Luke, London. 